\title{
CAUSES OF BACK-SILTATION IN THE NORTH PASSAGE OF YANGTZE ESTUARY AND EVALUATION OF THE ENGINEERING MEASURES
}

\author{
Qijin Fan ${ }^{1}$
}

\begin{abstract}
This study focused on the fact that the amount of back-siltation in the deep waterway of North Passage has been increased and converged in the middle reach since 2005. This paper systematically analyzed impacts resulting from the change of various factors such as sediment and hydrodynamics conditions, pointed out the major reason resulting in the increase on the amount of back-siltation in the middle reach, and discussed engineering measurements to reduce the siltation. The engineering effects of the measures were evaluated after the constructions as well.
\end{abstract}

Keywords: Yangtze Estuary; North Passage; reason of siltation; measures, engineering effect; evaluation

\section{BACKGROUND}

The general layout of the Improvement Project of the Deep-Draft Channel of the Yangtze Estuary is shown in Figure 1. Observations showed that the amount of back-siltation in the deep navigation channel of the North Passage had been continuously increasing and siltation concentrated in the middle reach since 2005 (Fig. 2). The maintenance dredging volume for the whole channel increased from 35.55 million $\mathrm{m}^{3}$ in 2005 to 57.67 million $\mathrm{m}^{3}$ in 2008. Meanwhile, the siltation concentrated at the middle reach, where $16 \mathrm{~km}$ long channel (from dredging unit $\mathrm{H}$ to unit $\mathrm{N}$ ) had $60 \sim 70 \%$ of the total siltation volume of the $74.4 \mathrm{~km}$ long channel (Fig. 2). Based on a systematical analysis on effect of the change of sedimentary and hydrodynamic conditions in the North Passage on the back-siltation, this paper points out major causes of the increase on amount of back-siltation in the middle reach and subsequently illustrates the proposed engineering measures to reduce the siltation. The proposed engineering measures have been implemented and proven to be effective.

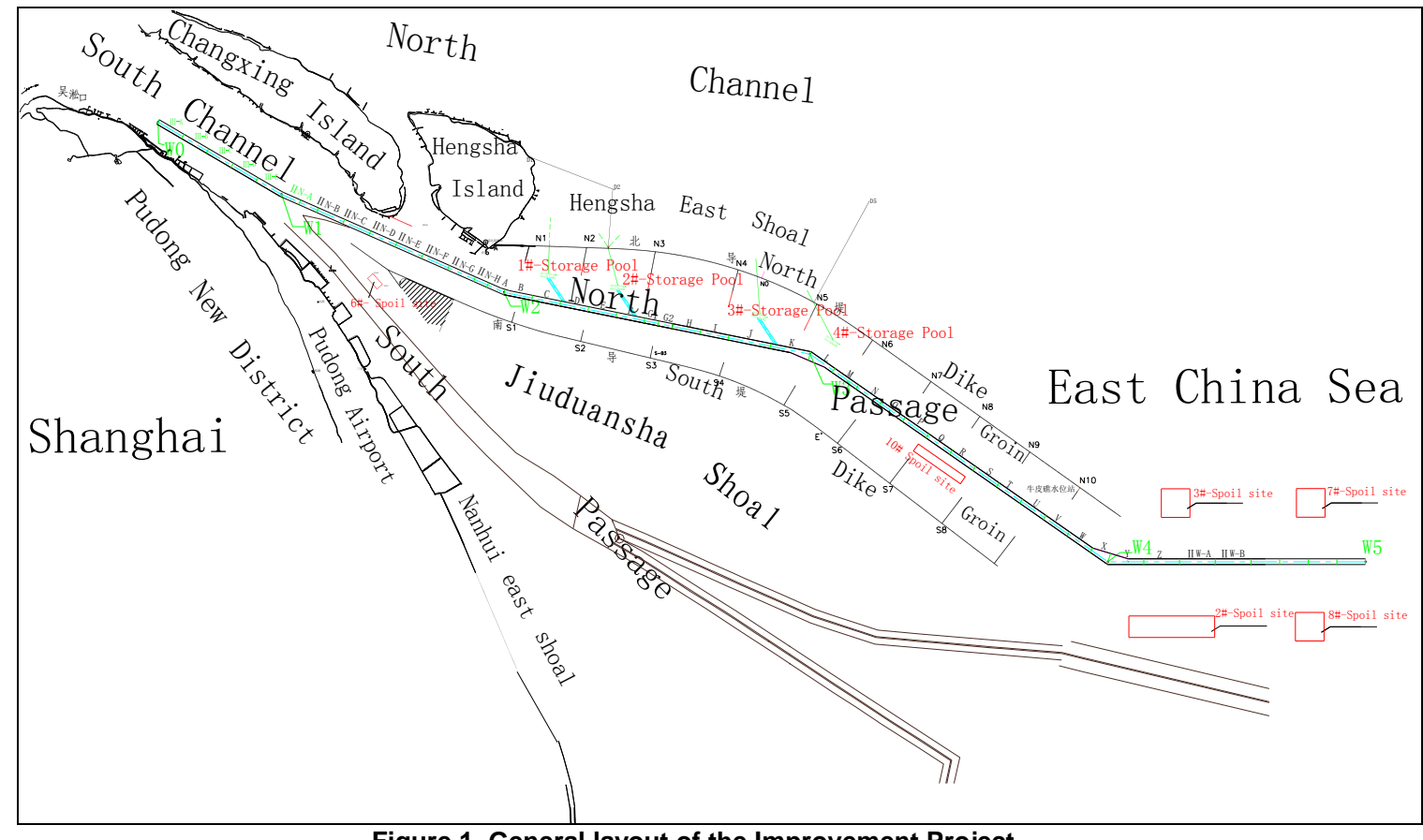

Figure 1. General layout of the Improvement Project

\footnotetext{
${ }^{1}$ Yangtze Estuary Waterway Administration Bureau, MOT. Floor 21, No. 48, Weihai Road, Shanghai, 200003,China
} 


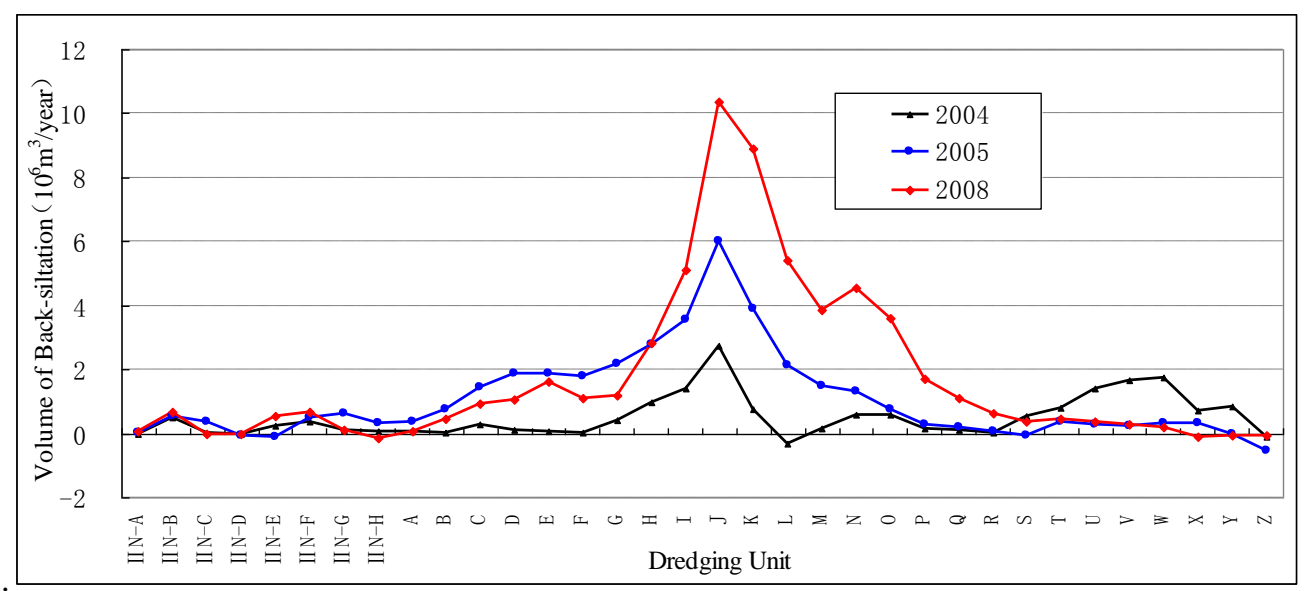

Figure 2. Annually back-siltation quantity distribution along the dredging unit (2004-2008)

\section{CAUSES OF BACK-SILTATION IN NORTH PASSAGE}

\section{Characteristics of Back-siltation}

The distribution of dredging units of the Improvement Project is shown in Figure 1. And the recent annual quantity of back-siltation and its distribution are shown in Table 1 and Figure 2.

\begin{tabular}{|c|c|c|c|c|c|c|c|c|c|}
\hline Year & 2000 & 2001 & 2002 & 2003 & 2004 & 2005 & 2006 & 2007 & 2008 \\
\hline $\begin{array}{l}\text { Total Siltation } \\
\text { Volume }\end{array}$ & 2369 & 2103 & 2097 & 1838 & 1705 & 3555 & 4150 & 6127 & 5767 \\
\hline Volume of Unit $\mathrm{H}-\mathrm{N}$ & 1155 & 733 & 550 & 1272 & 625 & 2121 & 2401 & 3922 & 4103 \\
\hline Ratio & $49 \%$ & $35 \%$ & $26 \%$ & $69 \%$ & $37 \%$ & $60 \%$ & $58 \%$ & $64 \%$ & $71 \%$ \\
\hline Remark & \multicolumn{4}{|c|}{$\begin{array}{l}\text { Maintenance } 8.5 \mathrm{~m} \text { Navigation } \\
\text { Channel After Phase I }\end{array}$} & $\begin{array}{c}\text { Capital Dredging } \\
\text { During Phase II } \\
\text { (10m water } \\
\text { depth) }\end{array}$ & \multicolumn{4}{|c|}{$\begin{array}{l}\text { Maintenance } 10.0 \mathrm{~m} \\
\text { Navigation Channel after Phase II }\end{array}$} \\
\hline
\end{tabular}

The main characteristics of back-siltation in North Passage are as the following:

- $\quad$ Since 2005, the annual quantity of back-siltation has been increasing, and the volume has exceeded the original prediction volume of 25 million $\mathrm{m}^{3}$.

- The back-siltation concentrated at the middle reach from the dredging unit $\mathrm{H}$ to $\mathrm{N}$. The volume of back-siltation in middle reach had $60-70 \%$ of the total volume, while the length of this reach is 16 $\mathrm{km}$, which is only $22 \%$ of the total length of the navigation channel.

- The feature of the back-siltation in the North Passage remains the same during the flood/dry season, which means that, first of all, the quantity of back-siltation during the flood season (May-October) contributes up $80 \%$ of that in a whole year, and the percentage has not been changed since the construction of Phase I; And the second, the back-siltation at the middle reach in the North Passage has similar feature to other reaches that the back-siltation quantities during wet/dry season are $80 \%$ to $20 \%$.

\section{Research Approach}

Normally, there are two forms of siltation in a navigation channel: bed load transport and sedimentation and suspended load deposition. The deposition is determined by the source and quantity of sediment and the physical and chemical properties of sediment, river morphology and hydrodynamic conditions and so on.

Therefore, in order to study the causes of high back-siltation in the waterway of North Passage, it's necessary to focus on the main features that the back-siltation increasing from 2005 and concentrating in the middle reach. Analysis is carried out from two aspects: the change of sediment transport conditions and hydrodynamic conditions. Sediment transport conditions include bed load and suspended load. Hydrodynamic conditions include the river bed morphology, such as the bed slope 
between channel and shoal which would influence the range of siltation, and flow field in crosssection and longitudinal profile, triggers of flocculation. Special attention are drawn on the influence of the sedimentary and hydrodynamic conditions changes on the amount of siltation in the middle reach in space, and the changes of sedimentary and hydrodynamic conditions before 2005 and after 2005 in time (Fan,2009).

\section{Change of Sediment Transport Conditions}

\section{(1) Sediment from the upstream}

\section{- Suspended load}

Measuring data from Datong station (located in the lower reach of Yangtze river, Anhui province), shows that the annually quantity of suspended load sharply decreased from 486 million ton to about 100 million ton in recent year, as is shown in Fig. 3. Correspondingly, the annual mean suspended sediment concentration (SSC) decreased from $0.5 \mathrm{~kg} / \mathrm{m}^{3}$ to $0.2 \mathrm{~kg} / \mathrm{m}^{3}$. Apparently the increase of back-siltation in the North Passage doesn't have clear relation to the change of suspended load from the upstream.

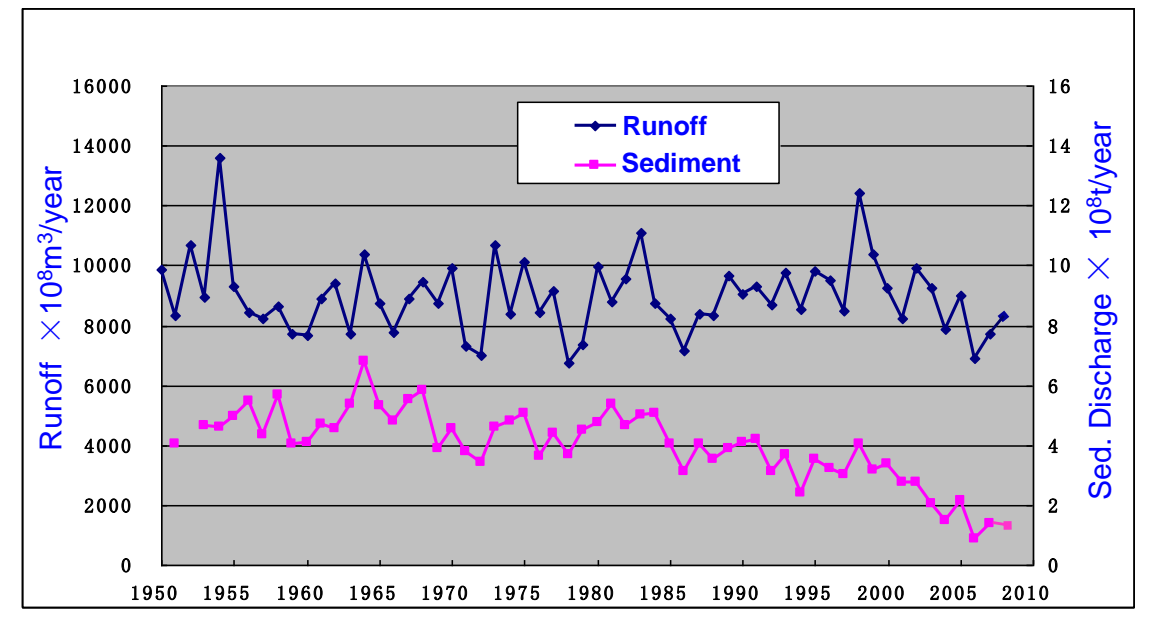

Figure 3. Variation of annual river runoff and suspended sediment discharge at Datong

\section{- Bed load}

In the upstream of North Channel, the main stream of South Channel is continuously deflecting northwards, which results in constant erosion of the middle part of Ruifensha Shoal. In addition to the illegal sand mining, the lower Ruifensha Shoal are under continuously shrinking. According to bathymetry survey from Feb. 2000 to Feb. 2007, the volume of Ruifengsha shoal above the depth of $10 \mathrm{~m}$ decreased 140 million $\mathrm{m}^{3}$. Thus several tens of millions of bed load goes into the North Passage along with the ebb currents, and it results in a continuous siltation in North Passage (Fig. 4).

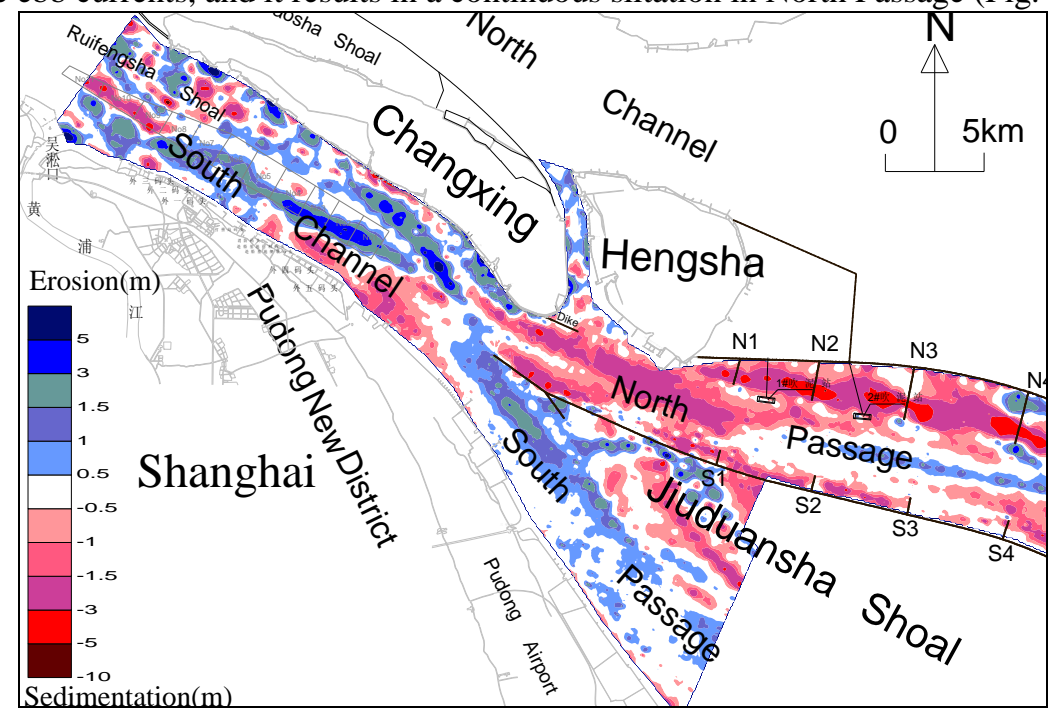

Figure 4. Morphological change in South Channel (2003.8 2005.11) 
The navigation channel is maintained above $10.0 \mathrm{~m}$ water depth by continuous dredging after completion of Phase II, while the side erosion/sedimentation on the flat beside the navigation channel could be regarded as the bed load transport process. The sediment eroding from Ruifengsha shoal would enter North Passage and move toward sea after a certain period. Figure 5 shows that, firstly, the bed load eroded from Ruifengsha Shoal entered North Passage and deposited at the side flat at the entrance of North Passage (dredging unit B, C and D) in 2004. Afterwards in the year of 2005, the entrance are restored by scouring and the deposition area moved to downstream and started to effect the middle reach (dredging unit F, G and $\mathrm{H}$ ), which increased the slope between side flat and channel at the middle reach and increased the deposition quantity of suspended load, consequently enhanced the backsiltation in the navigation channel of middle reach. After 2007, this deposition and erosion pattern has passed the middle reach and continuously moved along towards and then the middle reach are under erosion as a restoration (Fig. 6).

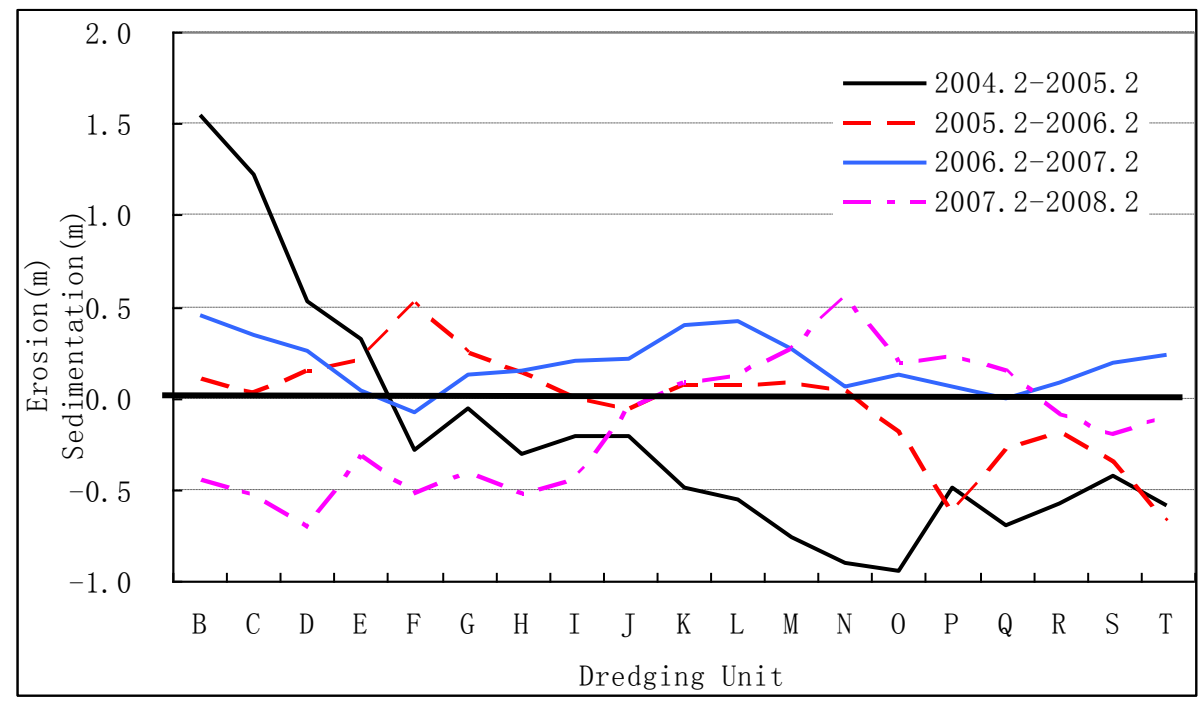

Figure 5. Erosion and sedimentation on the side flat along the North Passage

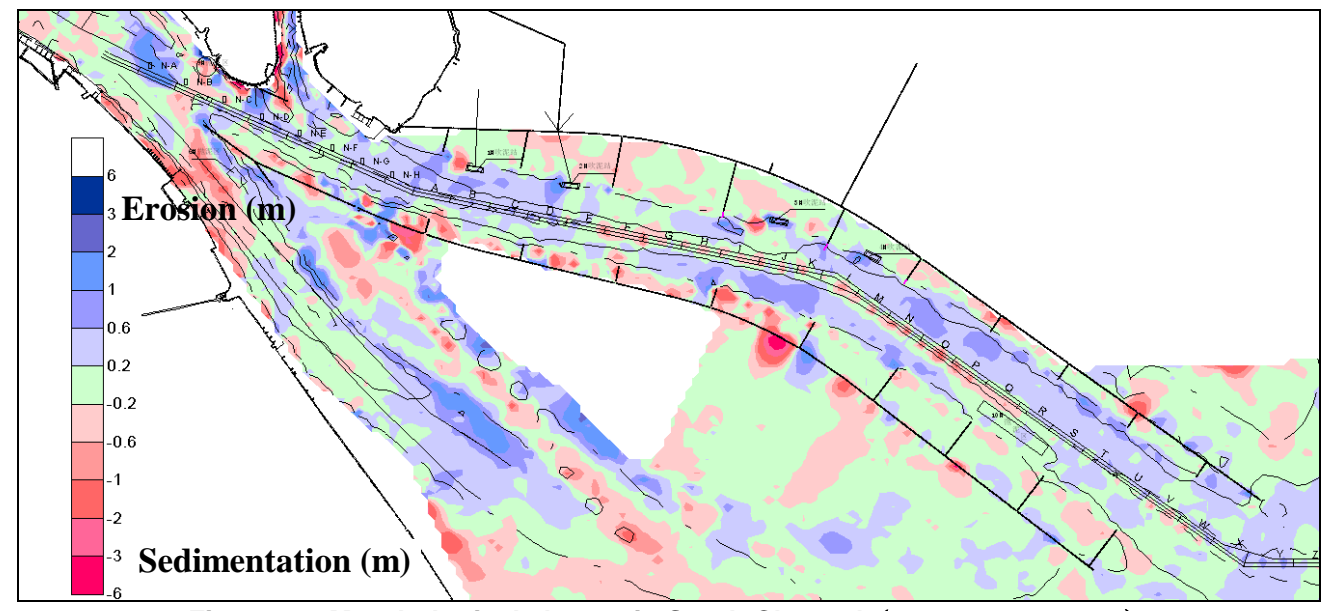

Figure 6. Morphological change in South Channel (2007.11 2008.11)

From Table 1, the quantity of back-siltation in 2004 is only 17.05 million $\mathrm{m}^{3}$, which is less than that of 2001-2003, the bed load transport did not effect the maintenance of 8.5m-depth channel at upper reach. On the contrary, with the obvious erosion of middle reach in 2007 , the quantity of back-siltation at dredging unit $\mathrm{H}-\mathrm{N}$ in 2008 still reached up to 41.03 million $\mathrm{m}^{3}$. It is clear that the bed load from Ruifengsha shoal is not the sediment source for the serious back-siltation in middle channel.

\section{(2) Sediment transport by flood currents}

In general, the relationship between SSC of in North Passage and tidal current could be summarized as the following: SSC is higher during the spring tide, and usually SSC during flood time is bigger than that of ebb time during spring tide. Observation data from Feb. 1991 to Mar. 1991 shows that, the average SSC is $0.623 \mathrm{~kg} / \mathrm{m}^{3}$ during ebb time while it reaches $0.912 \mathrm{~kg} / \mathrm{m}^{3}$ during flood time. 
The same trend is also shown in the North Passage as Figure $7\left(1.0 \mathrm{~kg} / \mathrm{m}^{3}\right.$ for flood time and $0.7 \mathrm{~kg} / \mathrm{m}^{3}$ for ebb time). It is more noticeable that the SSC is up to $1.83 \mathrm{~kg} / \mathrm{m}^{3}$ in flood time while $1.13 \mathrm{~kg} / \mathrm{m}^{3}$ in ebb time near W3 in the middle reach of North Passage.

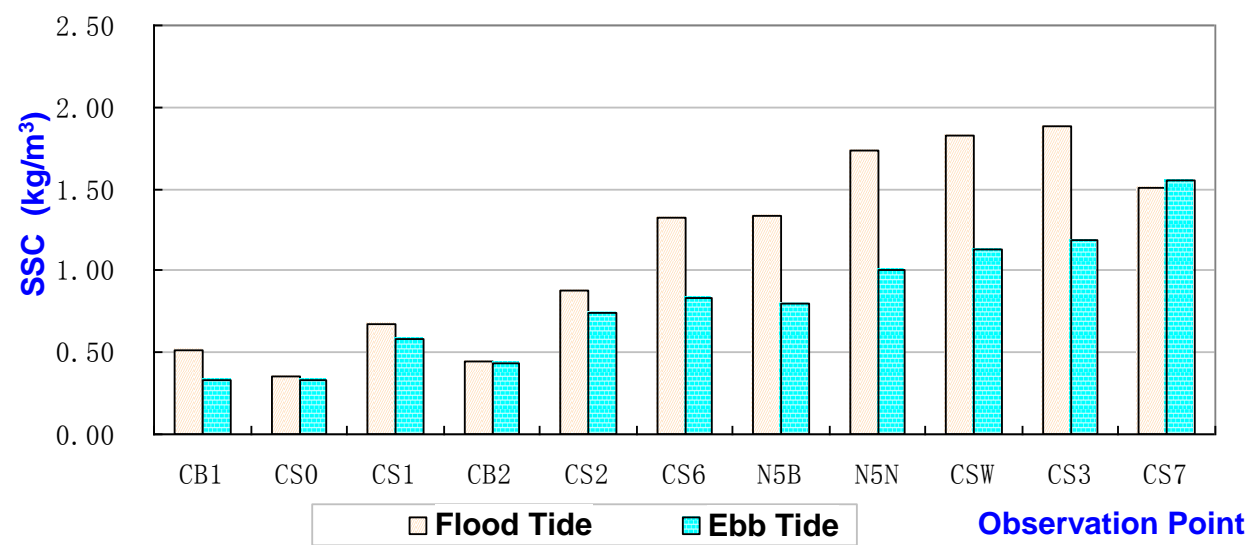

Figure 7. Depth averaged SSC during flood and ebb tide along the North Passage (2008.08)

Long period of observation data shows that, although the total amount of suspended load from Datong decreased sharply, at the lower reach of Yangtze Estuary from Hengsha Island, SSC almost keeps the same patterns for various seasons and tidal conditions, without significant variations before and after 1985. It implies that the value of SSC in the North Passage mainly depends on the tidal currents. Under the endless tidal circulation, the suspended sediment driven by the strong tidal current, with concentration of about $0.5 \sim 1.0 \mathrm{~kg} / \mathrm{m}^{3}$, is always the source of back-siltation of the channel.

With the decreasing sediment input from upstream, this pattern didn't change before and after the Phase II. Thus, the serious back-siltation in North Passage after 2005 is not due to the sediment transport from the outer sea.

\section{(3) Sediment supply from the side shoal}

Total volume of deposition in the groins areas (area between training dike and groins) in North Passage (totally 19 groins) has reached 3,000 million $\mathrm{m}^{3}$ since the Improvement Project was launched, where the bed level is continuously deposition up to about $0.0 \mathrm{~m}$ (above the reference datum) in some groins area (Fig. 8). Thus, during the typhoon or winter storm periods, fine sediment in the groin area is easy to be resuspended and transported out of groin area by waves and tidal current, which would increase the SSC nearby and then increase sudden back-siltation in the navigation channel (Fig.9).

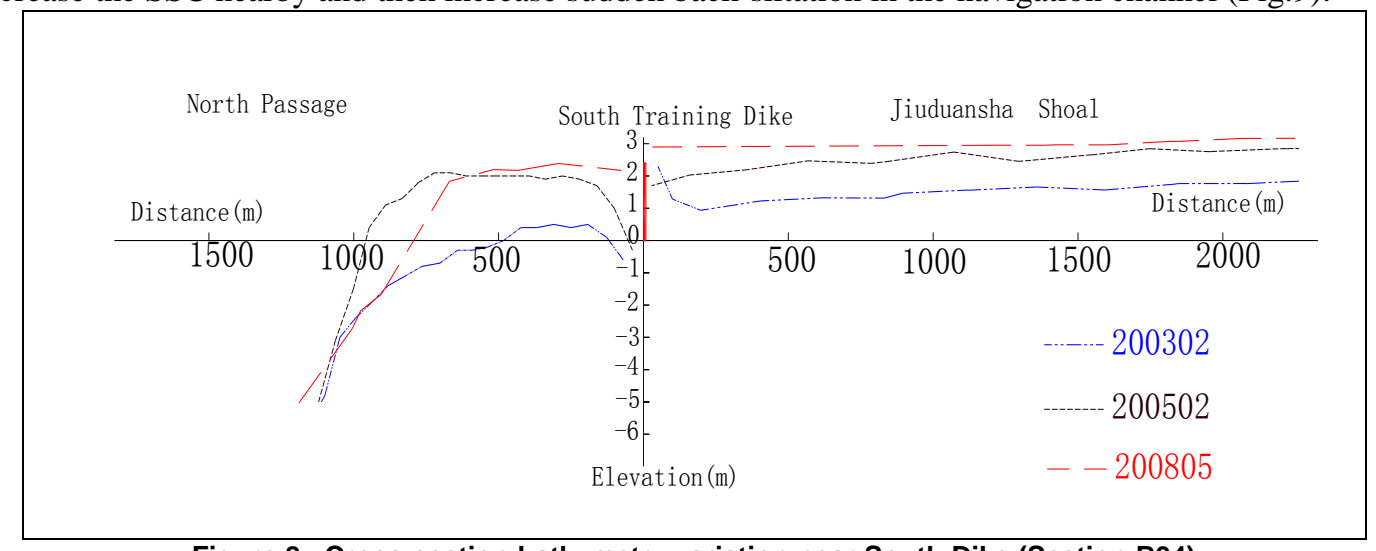

Figure 8. Cross-section bathymetry variation near South Dike (Section B34) 


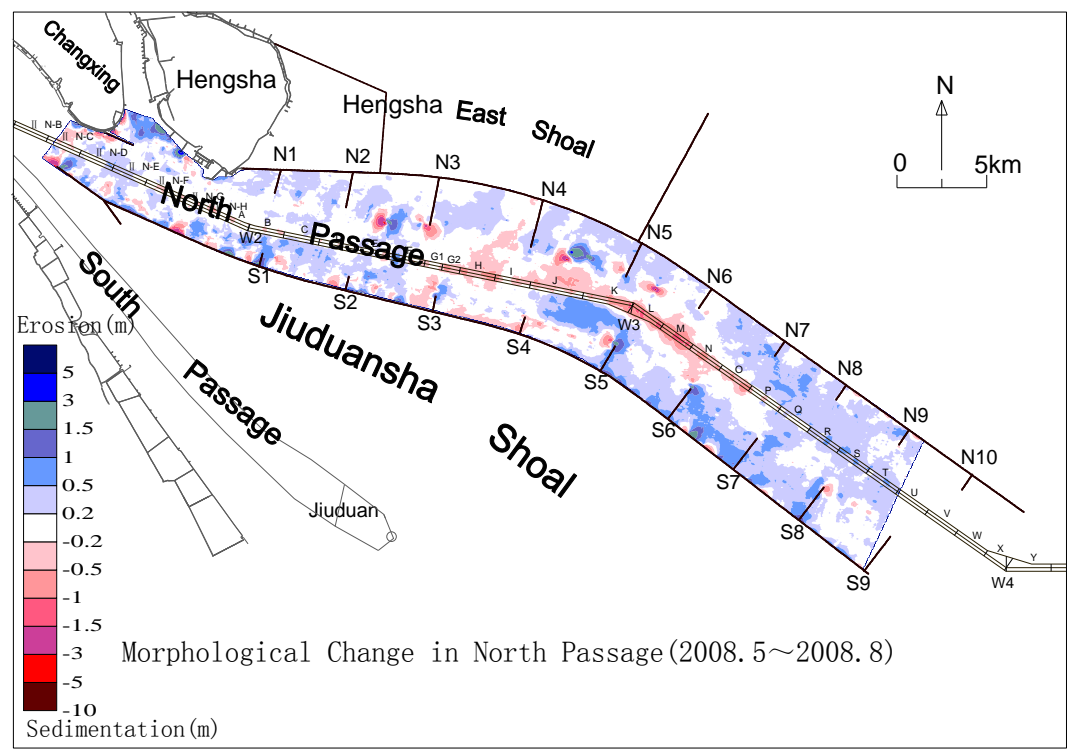

Figure 9. Morphological change in North Passage (2008.5 2008.8, during Phoenix Typhoon)

In recent years, significant deposition appears in the tidal flat area of Jiuduan shoal south of South Dike. At groin area between Groin S3 and S4, the bottom elevation has exceed $+2.0 \mathrm{~m}$ (above the reference datum). Measurement data along the cross-section from OBS also shows that the SSC rise remarkably during high waves period $\left(6 \mathrm{~kg} / \mathrm{m}^{3}\right)$, which is transported by tide current to the North Passage over the South Dike during flood time. The sediment resuspended from Jiusuansha Shoal and groin area also sediment source which contributes to the sudden back-siltation of navigation channel in middle reach.

Typical currents pattern of flood current and ebb current are shown in Figure 10. The directions of ebb/flood currents basically parallel to navigation channel axis, the max difference of the angle between currents and waterway is less than 10 degree. Extensive studies illustrated that the direction of the sediment transport to lower reaches in North Passage prefers to the southern side flat, and the transverse slope of side flat is less than $1 / 100$. Thus, it is believed that sediment can hardly be washed away by currents directly from side flat to channel. The sediment exchange between the side flat and the channel in North Passage, or we can say the reason of the sediment being transported to the channel from side flat, is mainly due to wave stirring up the sediment on side flat, suspended sediment concentration increasing, after water interchange and diffusion, the sediment deposits in the channel area from suspended load and increases the volume of siltation.

However, only typhoon and storm periods are too short to cause such severe and sudden backsiltation in the middle reach. Most of siltation in middle reach of North Passage is continuously occurring during the calm weathers. Therefore, it is believed that the sediment transported from side flat is also not a main reason to the high back-siltation in North Passage.

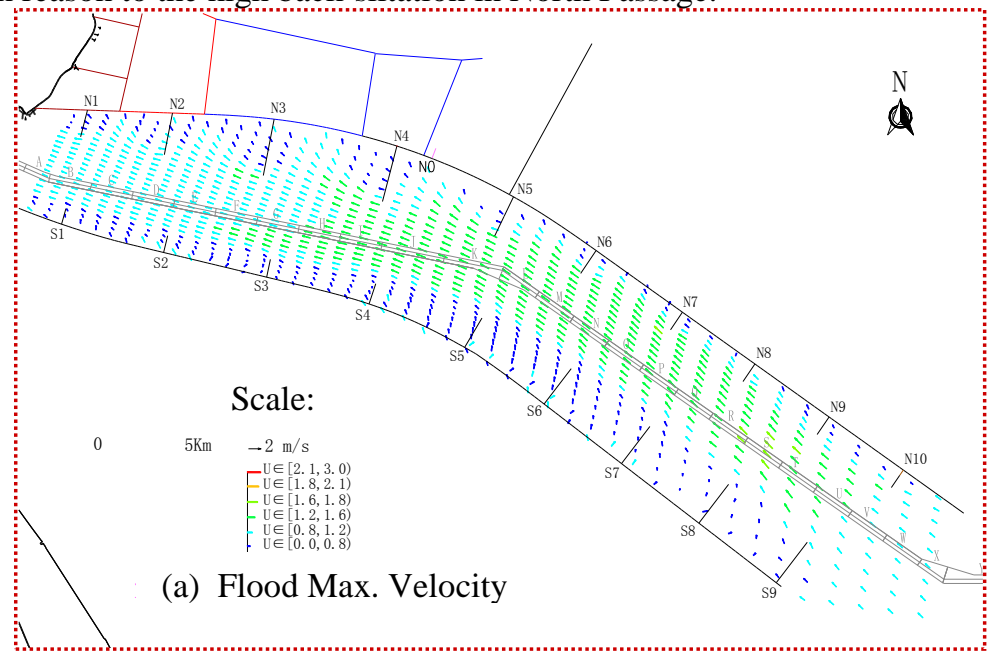




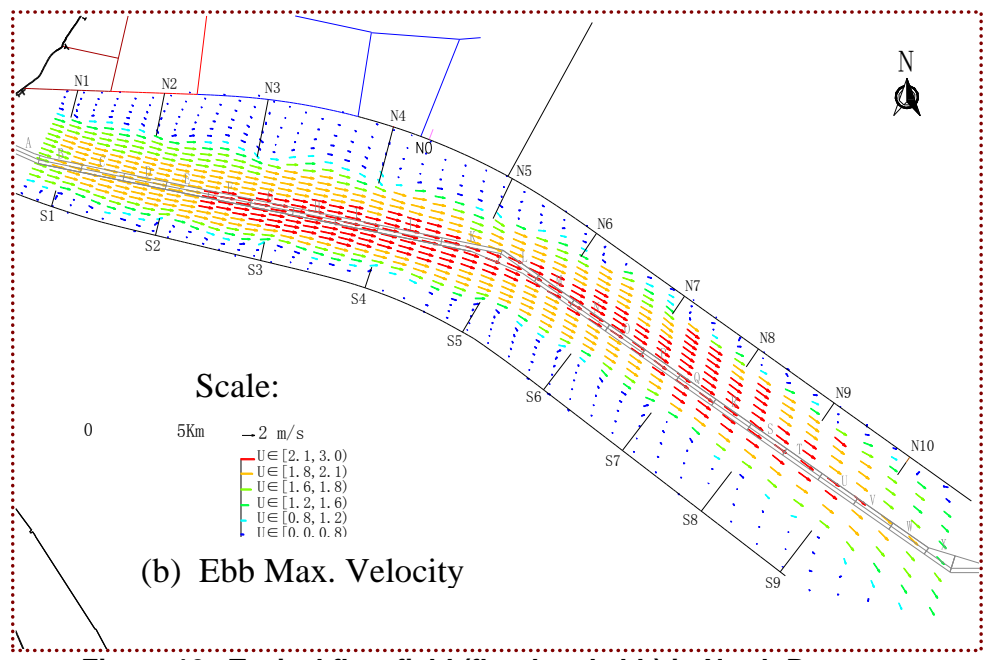

Figure 10. Typical flow field (flood and ebb) in North Passage

\section{(4) Loss of Dredged Material}

Since construction of Phase II, 4 storage pools and 1 dumping area (10\#) have been built between the North and the South training dike in North Passage after 2005 (Fig. 1). The original purpose is to improve the level of beneficial use of dredged material and to reduce the investment. The four storage pools are used for dumping dredged material from upper and middle reaches of navigation channel in North Channel by Training Suction Hopper Dredger, and the Cutter Suction Dredgers pump the dredged material from storage pools to north of North training dike for reclamation. The 4 storage pools and 10\# dumping area were heavily employed after 2005. According to extensive monitoring, including field survey on flow and sediment, ADCP measuring the diffusion of those dumping material, near bed tripod observation, neutron sediment tracer test, and numerical and physical modeling, it is found that $60 \% \sim 70 \%$ sediment dumped in the storage pools escapes away from the storage pools [5]. As a result, it increases the SSC nearby and then $7 \% \sim 11 \%$ of amount returns to the navigation channel. Later on, the operation and management of the dredging work in the Yangtze Estuary are optimized finally and the rate of loss decreases 6\% 19\% (Zhu, 2008).

From the beginning to 2008, according to the measurement, the total quantity of dredged material dumped in the 4 storage pools was up to 90.23 million $\mathrm{m}^{3}$, even if with the assumption that $10 \%$ of them returns to the navigation channel, the amount is only 9.02 million $\mathrm{m}^{3}$, which is still much less than several tens of million $\mathrm{m}^{3}$ back-siltation each year after 2005. So the loss of dredging material from the dredging operation is also not the main reason for the severe back-siltation either.

\section{(5) Features of sedimentation of the mouth bar area}

Middle reach of North Passage is located close to the mouth bar of Yangtze Estuary before the Improve Project, where the median diameter of suspended sediment is about $0.01 \mathrm{~mm}$ with the fluid salinity is $5 \% \sim 15 \%$. It is the preferable area for flocculation. This area also found to be the estuarine turbidity maximum area, saltwater wedge, and the currents stagnation zone. It has been the area with serious sedimentation with long history. Because of the water temperature in summer is higher than that in winter, and high water temperature enhance the sediment flocculation, the value of SSC in summer is greater than that of winter, resulting in which the back-siltation is generally higher in summer time than in winter time.

Before and after 2005, the amount of back-siltation in the middle reach during the flood seasons contributes $80 \%$ of the amount of the whole year, which is in accordance with the properties of fine sediment flocculation. It also implies that the original features of mouth bar area in the middle reach didn't change after the Improvement Project, and the serious back-siltation in the middle reach also doesn't have no direct relation with the sediment flocculation.

Nevertheless, the characteristics of back-siltation concentrating in the middle reach and the amount of sedimentation in flood seasons is much higher than that in dry seasons, which is similar to the features of sediment flocculation in this area. It shows that the deposition in North Passage is mainly from suspended sediment instead of bed load, because the flocculation is only relating to suspended sediment. 
In summary, all the sediment resources mentioned above have some effects on the back-siltation in the channel, but they all are not the main reasons for the severe siltation after 2005. It's difficult to quantify the influences of the change of each sediment conditions with the present measures and theories, and it is also almost impossible to change those sediment transport conditions and reduce the amount of back-siltation by any engineering measures.

\section{Variation of Hydrodynamic Conditions}

\section{(1) Changes of discharge at Datong station}

As is shown in Figure 3, the annual runoff at Datong remains 900 billion $\mathrm{m}^{3}$ per year without obvious change.

\section{(2) Change of flow hydrodynamics along the Channel}

The regulating structures (dikes and groins) of Phase II of the Improvement Project were completed in Dec. 2004, and the navigation channel was dredged to $10.0 \mathrm{~m}$ water depth in Mar. 2005. Therefore, to explore the effects of flow field on the back-siltation and its distribution at the Navigation Channel of North Passage, the change of hydrodynamics conditions before and after the Phase II in North Passage should be focused on.

Before the Phase II, maintenance dredging in North Passage was comparatively smooth. Concerned to the maintenance volume in the whole channel and the middle reach, the workload is still acceptable and the hydrodynamics condition was quite well.

Numerical modeling results showed flood/ebb max velocity along the channel axis before and after the constructions of Phase II (Figure 11 and Figure 12). The bathymetry and engineering works conditions in the numerical model are from field survey with construction program of the engineering work, and the hydrodynamic boundary conditions was kept same for the comparison.

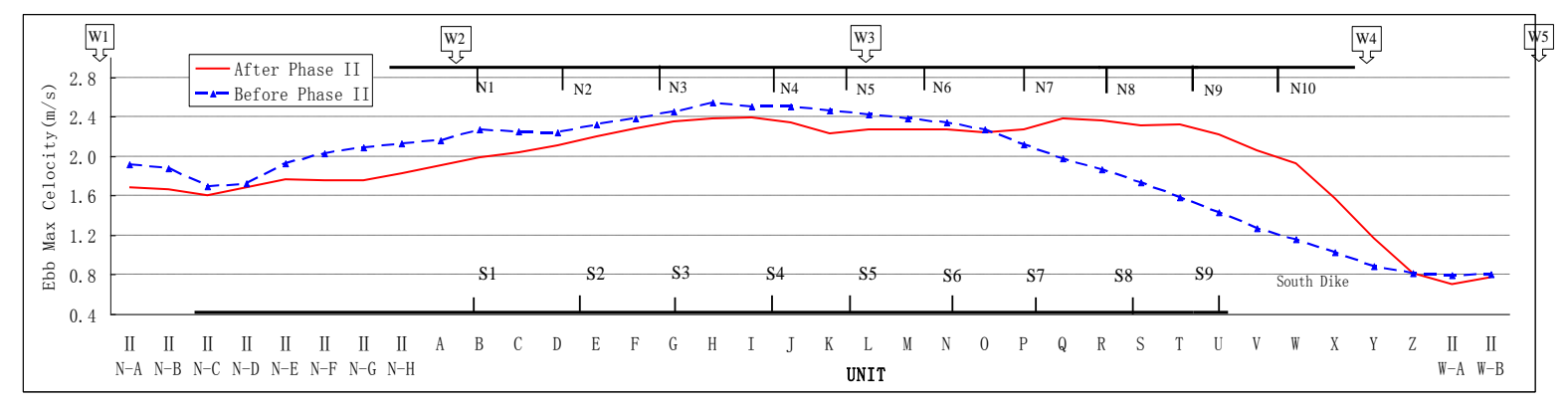

Figure 11. Max ebb velocity along the channel before and after the Phase II

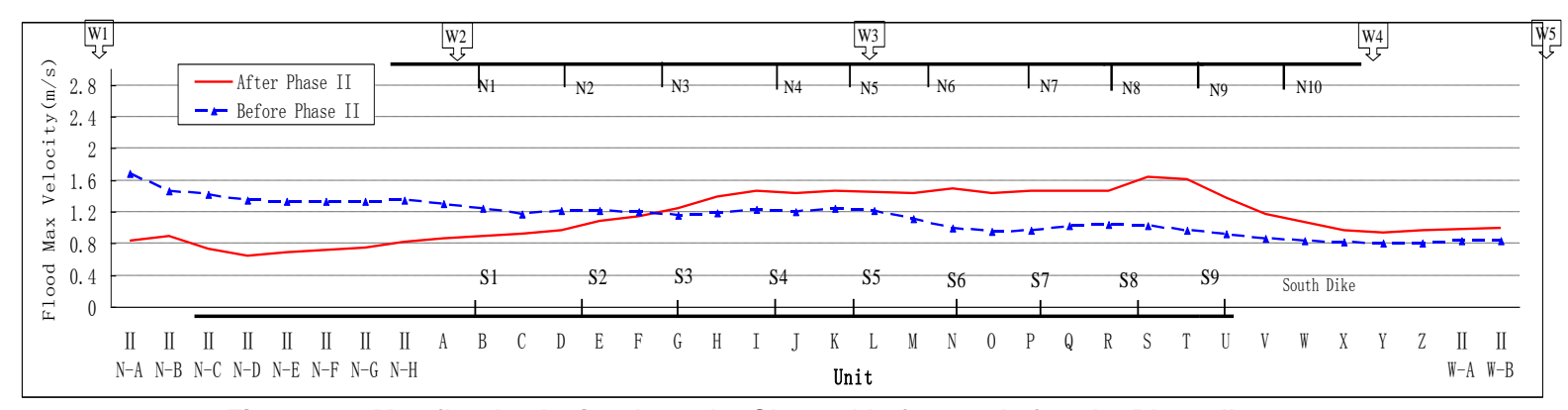

Figure 12. Max flood velocity along the Channel before and after the Phase II

Figure 11 showed that max ebb velocity in unit $\mathrm{H} \sim$ unit $\mathrm{N}$ was the largest compared with that in the upper and lower reaches before Phase II. After Phase II, max ebb velocity lower than unit O increased sharply, especially near groin $S 9$ it increases about $70 \mathrm{~cm} / \mathrm{s}$; while at the upper reach of unit $\mathrm{O}$, max ebb velocity declines obviously, it decreases about $20 \mathrm{~cm} / \mathrm{s}$ near W3. Therefore, the increasing in lower reach and decreasing in upper reach of the longitudinal distribution of the hydrodynamics condition makes the max ebb velocity in middle reach lower than that of lower reach and even lower than its upper reach. Especially at the middle reach from unit I to unit P, it forms a relatively low valley, which results in the decreasing of the sediment transport capacity in the middle reach.

In Figure 12, max flood velocity in the upper reach of groin N3 decreases while the range of decreasing is bigger than the decreasing range of max ebb velocity. Max flood velocity in the reach 
lower than groin $\mathrm{N} 3$ increases as a whole, while in the lower reach of unit $\mathrm{P}$, the range of increasing is smaller than the increasing range of ebb max velocity. In general, although max ebb velocity in upper reach is decreasing, it is still ebb dominant, and the ebb hydrodynamics increase remarkably in lower reach. Only in the middle reach, the ebb hydrodynamics decreases and flood hydrodynamics increase, this results in the declining of sediment transport capacity of ebb current, and thus a hydrodynamic environment favorable to sedimentation. The difference of horizontal velocity pattern before and after Phase II is similar to the trend inside the channel.

\section{(3) Change of sediment transport capacity}

According to flow field, the suspended sediment transport capacity can be calculated. The net capacity of sediment transportation before and after Phase II is showed in Figure 13 and Figure 14(Qi, 2007).

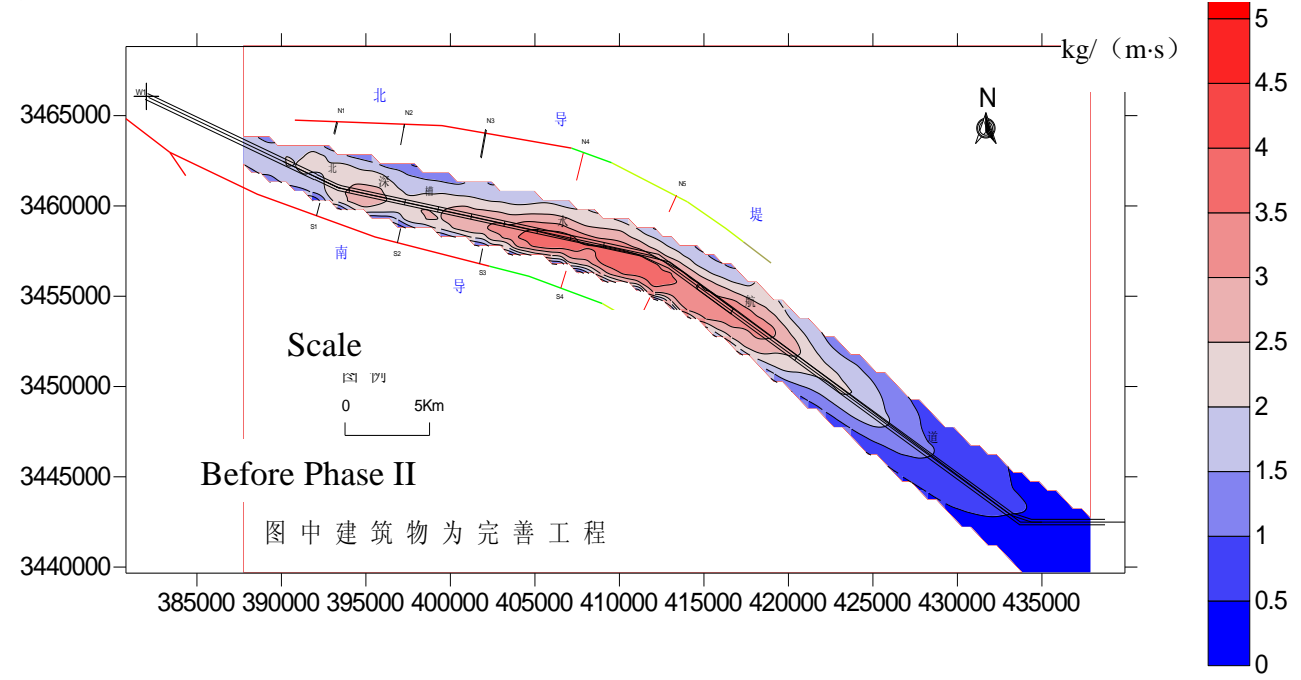

Figure 13. Suspended sediment transport capacity of North Passage before Phase II

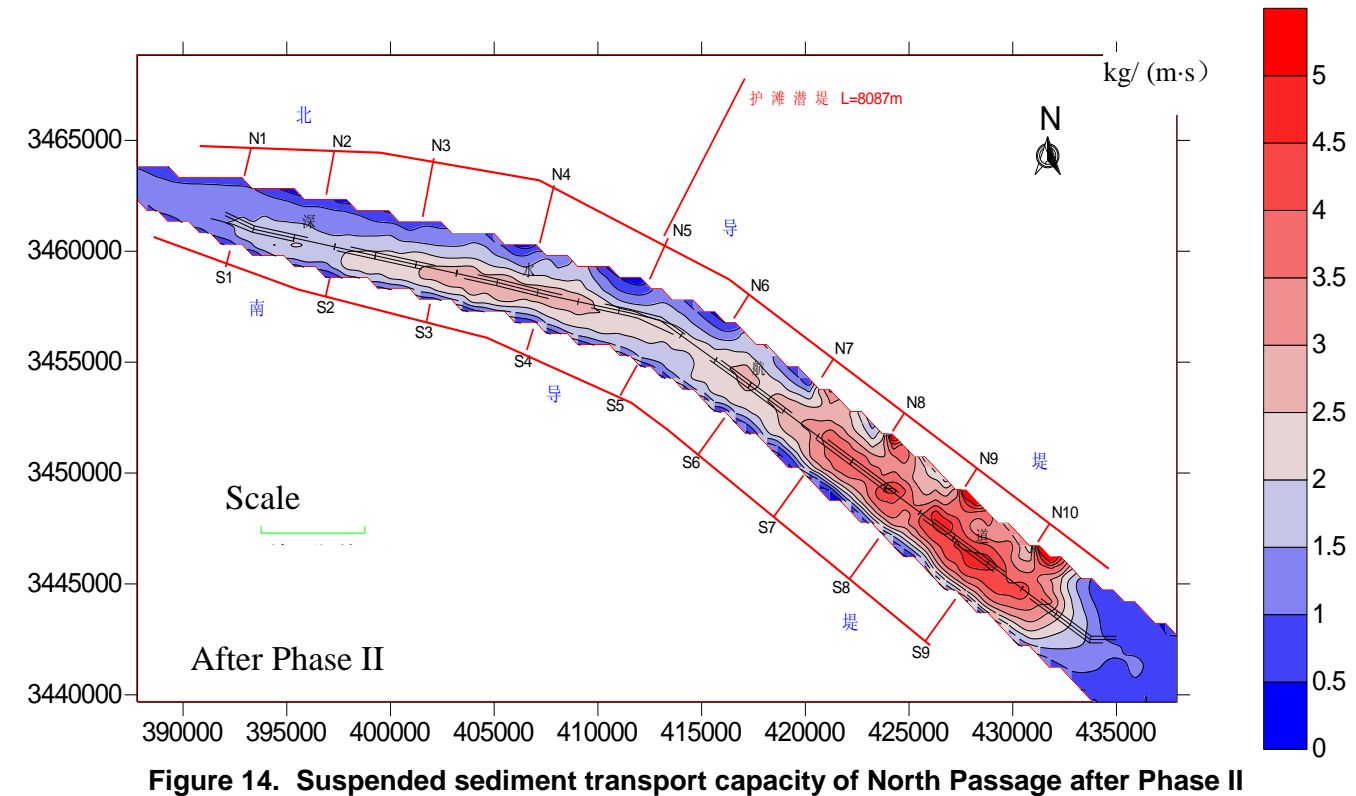

Figure 13 showed that before the Phase II, the suspended sediment transport capacity near W3 (the middle reach) is the highest of the whole channel, so the sediment can not easily deposit at this reach. It shows that although the middle reach is near mouth bar where sediment deposition is preferable, but it has relatively strong local hydrodynamics and thus high suspended sediment transport capacity, the maintenance of the navigation channel is not very difficult before the Phase II.

However, Figure 14 showed that, after the Phase II, the suspended sediment transport capacity in lower reach of the North Passage is higher than that before the Phase II, and the channel depth in the lower reach increased naturally without maintenance volume for $10.0 \mathrm{~m}$ channel. But in the middle near 
W3, where the suspended sediment transport capacity is lower than its upper and lower reaches, it is favorable for high deposition of suspended sediment.

In time domain, the time point of the changes of hydrodynamic conditions is coincided with the time table of the rapid back-silation in North Passage. And in space domain, the decline of hydrodynamic conditions is located at the middle reach where the volume of the back-siltation is up to $60 \% \sim 70 \%$ of that in the whole channel. The changes of hydrodynamic conditions are distinctly related to the characteristics of back-siltation of the channel of North Passage after 2005. The changes of hydrodynamic conditions are regarded as the major reason for the severe siltation in the middle reach.

\section{RESEARCH ON ENGINEERING MEASURES FOR SILTATION REDUCTION}

Based on the analysis above, general ideas for the siltation reducing in North Passage were proposed as below:

By extending the length of several specific groins in North Passage, to narrow the river width and to increase the ebb dynamics and sediment transport capacity substantially in the middle reach and adjacent upper and lower areas, with minimum negative effects on the ebb dynamics of the upper and lower reaches. The extending of groins should be considered comprehensively on its effect on longitudinal and transverse distribution of flow hydrodynamics. The change of longitudinal hydrodynamics distribution should be gentle, while the transverse hydrodynamics distribution should positively improve river bed shape and reduce siltation.

After several rounds of feedback-updating-modeling iterations, including field survey, numerical and physical modeling, the layout of the engineering measure for reducing siltation, named YH101, was proposed in 2008 (Fig. 15). The length of 11 groins, N1 N6 and S3 S7, were extended by $4621 \mathrm{~m}$ in total.

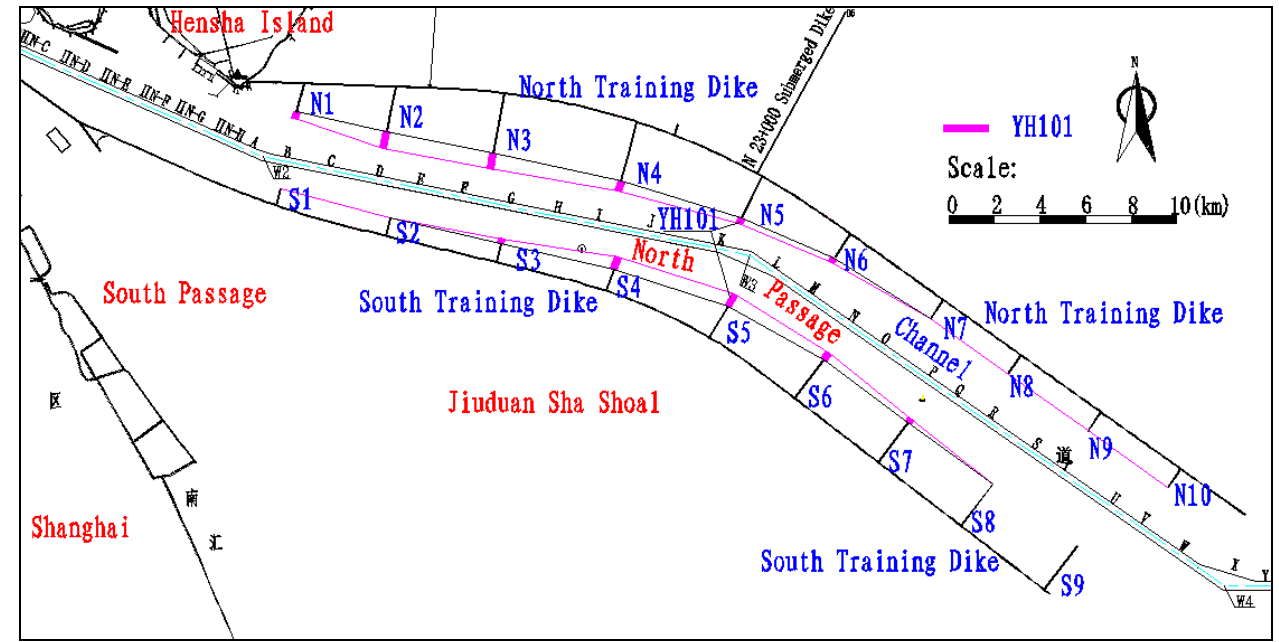

Figure 15. General layout of scenario YH101

Through the comparison of the max flood/ebb velocities along the channel before and after the YH101 (Figure 16 and Figure 17) we could see that, after YH101, the max ebb velocity near the unit $\mathrm{E} \sim \mathrm{P}$ increases by $0.06 \sim 0.41 \mathrm{~m} / \mathrm{s}$, the biggest increase amplitude locates at unit $\mathrm{J}, \mathrm{K}$ and $\mathrm{L}$, where the most serious area for siltation. From longitudinal distribution of the max ebb velocity after YH101, the biggest magnitude of max ebb velocity locates at the middle reach, and it slowly moves downward to the upper and lower reaches. It is a positive change, compared to the present situation that max ebb velocity is smaller than the upper and lower reaches and the sediment was not easily transported towards the open sea.

It also can be found that max ebb velocity of the entrance area (upper from groin S2) and the exit area (lower than groin S7) decreases with a small value. But since these two areas are not the focused reaches with serious siltation, and the lower reach has relatively higher sediment transport capacity, they are not expected to form new areas with heavy siltation. 


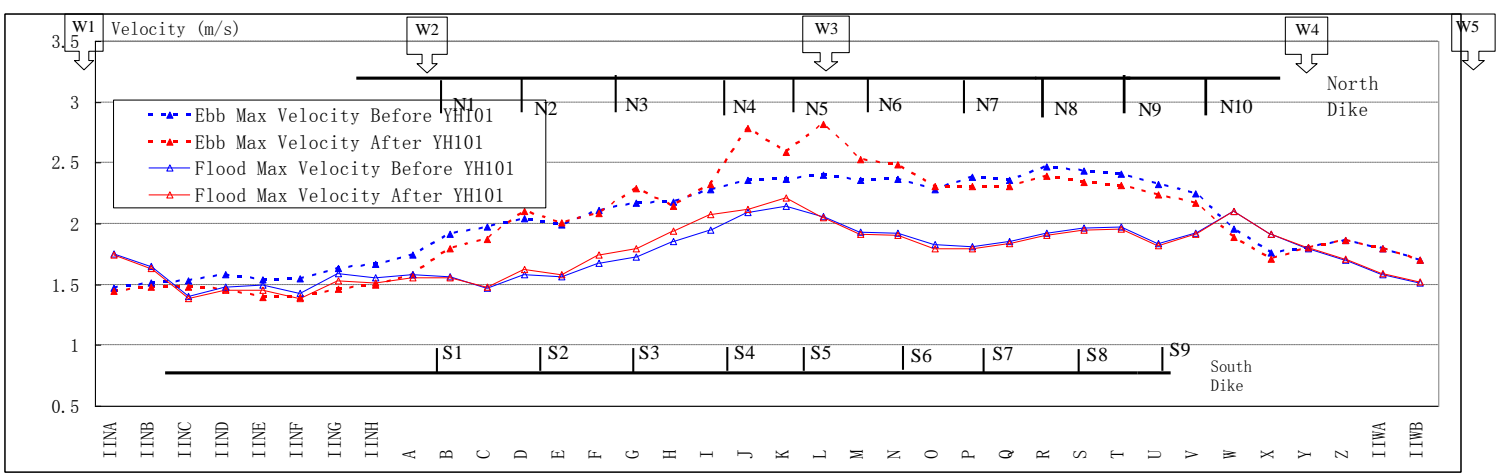

Figure 16. Comparison of max flood/ebb Velocity along the Channel before and after YH101

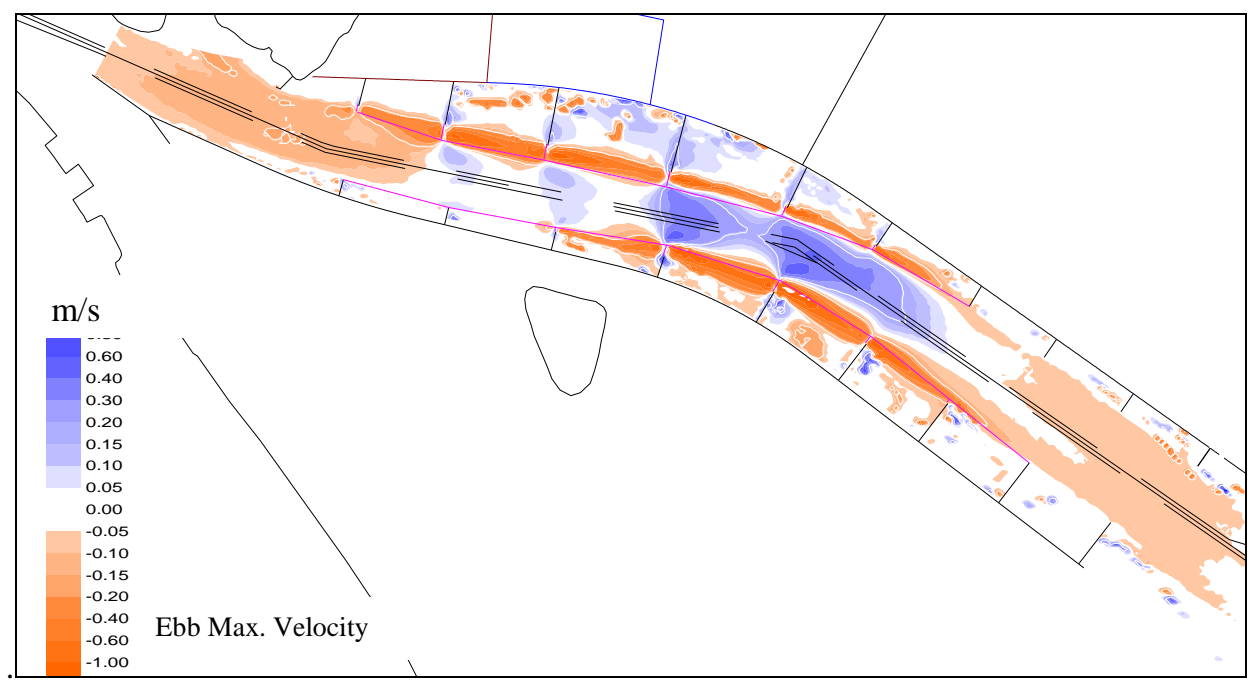

Figure 17. Difference map of the Max Ebb Velocity before and after YH101

\section{EVALUATION OF THE ENGINEERING EFFECT OF YH101}

The construction of YH101 was started in December, 2008 and was completed on 23rd April 2009. In situ monitoring of changes of sedimentary and hydrodynamic conditions, morphology changes of the river bed and the amount of back-siltation in the channel after completion of YH101 showed that the back siltation had been remarkably reduced. The flow field in the North Passage was also more favourable with enhanced ebb dynamics in the middle reach, especially in the main channel area. In addition, the cross section of the river bed has been adjusted to be narrower and deeper. As a result, the amount of back-siltation was reduced, and the depth in the navigation channel was increased.

\section{Improvement of Flow Field}

Figure 18 shows the distribution of depth average ebb velocity along the channel, which is from the measurement data of ADCP along the channel of middle reach measured within half hour by four survey boats and it could be regarded as the synchronous longitudinal average velocity distribution of middle reach. Due to the fact that the boundary conditions of river runoff and tide are different during the two surveys, a qualitative analysis is carried out to compare the difference of hydrodynamics before and after YH101.

- $\quad$ Before construction of YH101 (May. 2008), ebb velocity in the middle reach around unit I L is lower than that at the nearby unit.

- Although the river discharges at Datong and tide range in Aug. 2009 is bigger than that of May. 2008, from the shape of longitudinal distribution of ebb velocity, the low velocity area disappears and emerges a high velocity area in unit I N of the middle reach in 2009 after YH101. The change of distribution of longitudinal ebb velocity is similar with the results from the previous numerical modeling, the ebb hydrodynamic in middle reach is strengthened and the longitudinal distribution of the flow field is improved after the construction of YH101. 


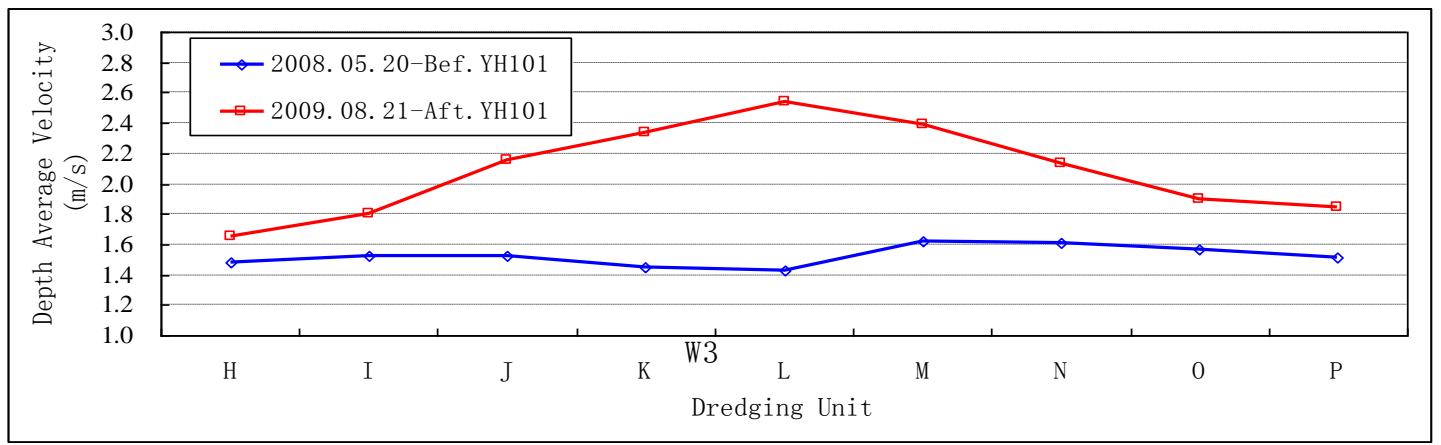

Figure 18. Comparison of Depth Average Ebb Velocity from the ADCP before and after YH101

\section{Bathymetry Adjustment and Main Channel Depth Improvement}

Figure 19 shows the bathymetry change between Feb. 2009 and May. 2010 (before and after YH101). The area among the extended groin is under continuously deposition for $0 \sim 4 \mathrm{~m}$, while the side flat area between the new north and south groins heads, is under continuous erosion. At the entrance area upper than groin $\mathrm{N} 1$ and $\mathrm{S} 1$ of North Passage the deposition is around $0 \sim 1.0 \mathrm{~m}$. The side flat between N1 N5 and S1 S5 shoal area of the upper reach is eroded for 0 3.0m. The lower reach between S5 S7, south side flat is deposited for $0 \sim 2 \mathrm{~m}$, while north side flat has some erosion. There is no significant change at the river reach lower than S7. In general, the morphological change of North Passage before and after YH101 can be summarized as the side flat between the extended groins is eroded and the new groin area is deposited, the rive shape is changed to narrow and deep. The morphological change is similar to the prediction from the scaled physical model.

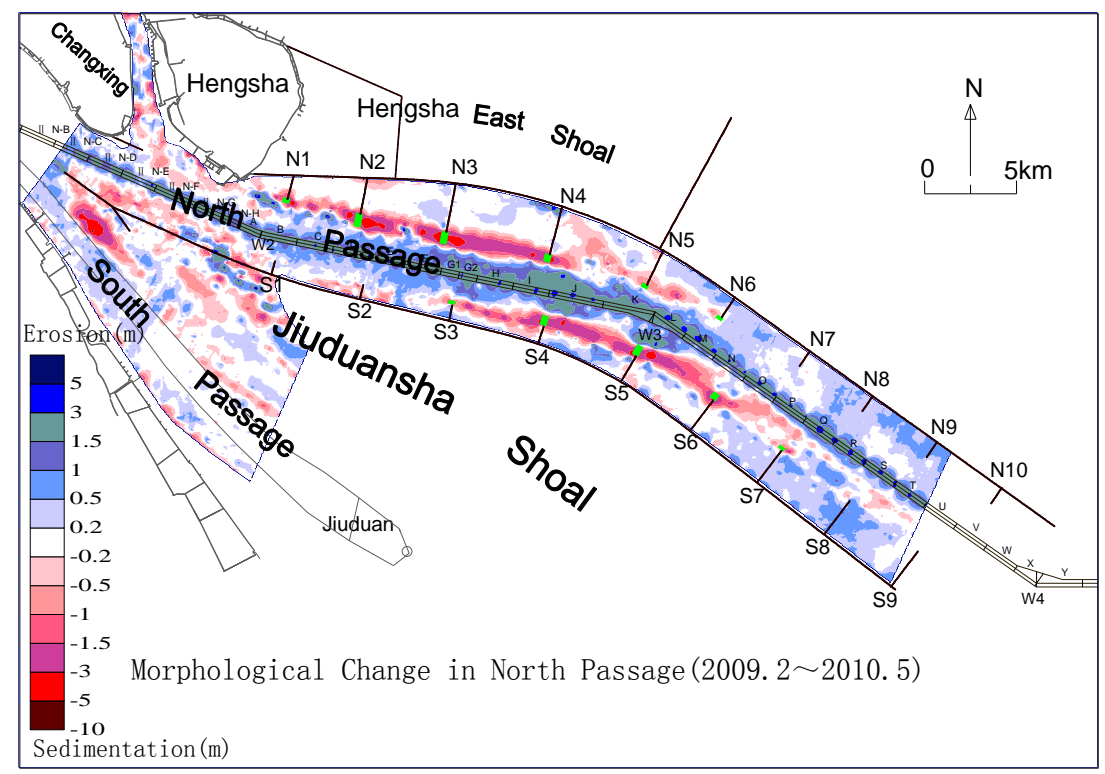

Figure 19. Morphological changes before and after the YH101 (Feb. 2009 to May 2010)

\section{Channel Depth Increase and Siltation Reduction}

Figure 20 shows the comparison of water depth along the navigation channel from Sep. 2006(at he beginning of Phase III), Jan. 2009(before YH101) and Mar. 2010(after YH101). During the construction time, from Sep. 2006 to Jan. 2009, the channel depth had no change, the average water depth of the channel decreased from $10.54 \mathrm{~m}$ to $10.52 \mathrm{~m}$, and the rate between bed measure to barge measure is less than 0 . While after YH101, with the increasing dredging capacity, the channel depth increases remarkably, the rate between bed measure to barge measure is up to 0.51 and water depth increased to $13.06 \mathrm{~m}$ in Mar. 2010. The average water depth increased $2.52 \mathrm{~m}$. 


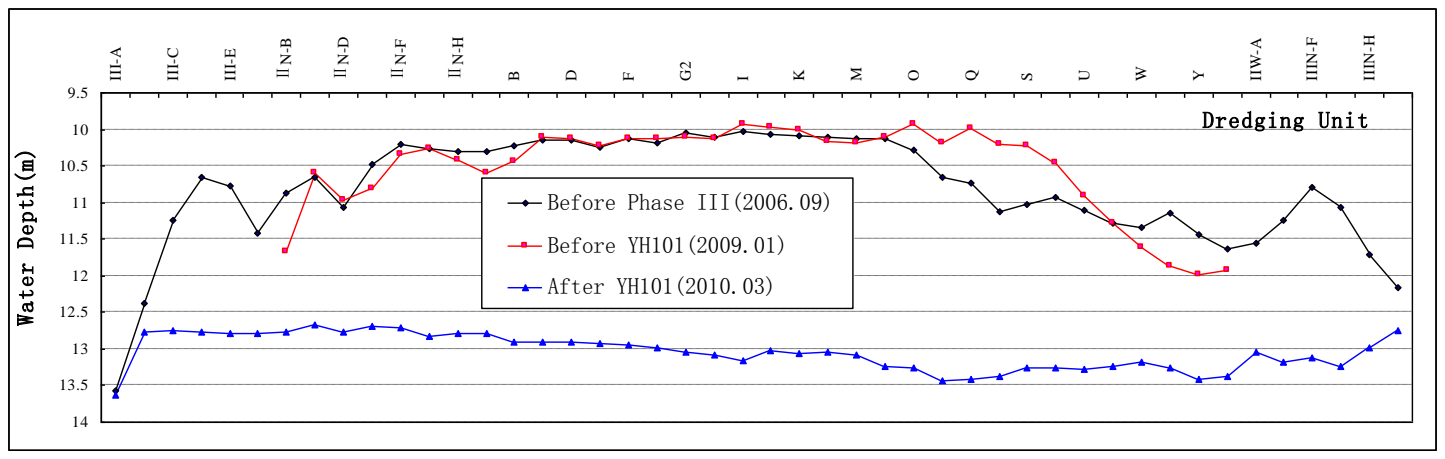

Figure 20. The process of water depth along the channel from Jan. 2009 to Mar. 2010

Figure 21 shows the comparison of average monthly height of siltation along the channel during period Apr. 2008 to Mar. 2009(one year before YH101), and period Apr. 2009 to Mar. 2010(one year after YH101). The average water depth in the first period is about $10.5 \mathrm{~m}$, and the total amount of the back-siltation is 56.44 million $\mathrm{m}^{3}$, the volume in the unit $\mathrm{H} \sim \mathrm{N}$ is up to 40.01 million $\mathrm{m}^{3}$. While during the second period, the average water depth is $11.8 \mathrm{~m}$, which is $1.3 \mathrm{~m}$ deeper than that of first period, and the quantity of back-siltation is 52.44 million $\mathrm{m}^{3}$ by a decrease of $12 \%$ compared to that of the first period, and the value in middle reach is only 27.47 million $\mathrm{m}^{3}$ by a decrease of $31 \%$. It's estimated that, under the same maintenance water depth of the channel, the effect on reduction back-siltation of YH101 is up to about $30 \%$.

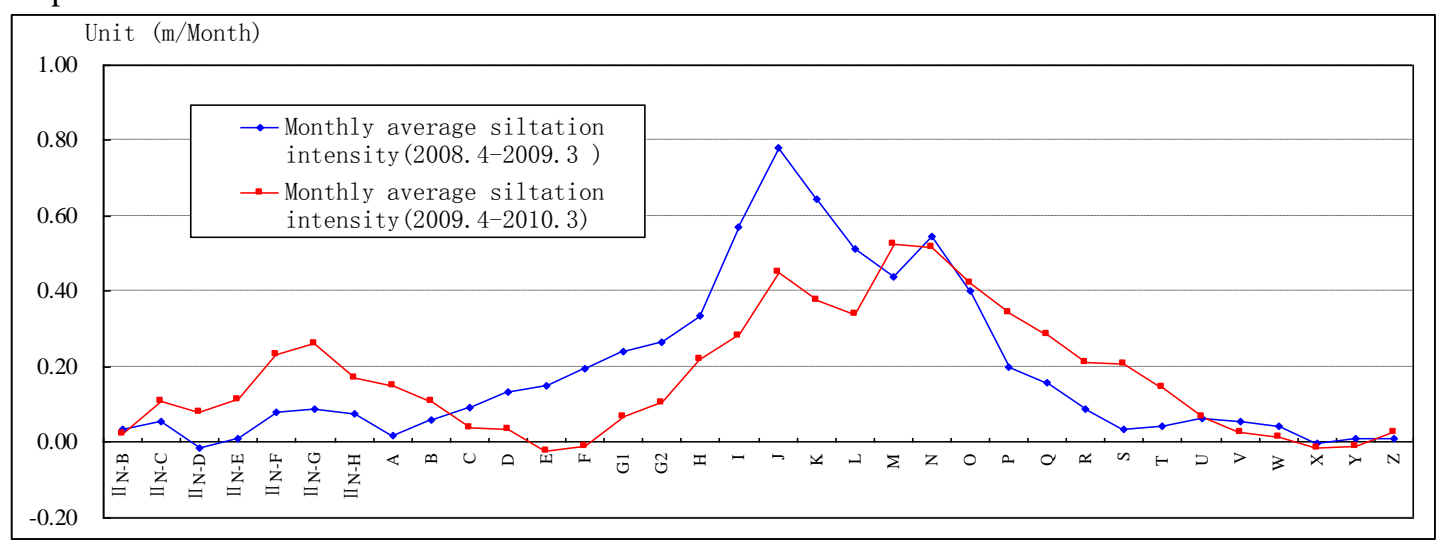

Figure 21. Average Monthly Height of Siltation along the channel during 2008.04-2009.03 and 2009.04-2010.03

The back-siltation distribution along the channel after YH101 is quite different for different reaches. The big volume of back-siltation in unit $\mathrm{I}, \mathrm{J}$ and $\mathrm{K}$ of middle reach has been reduced and changed to be similar to other reaches. Meanwhile two secondary peak values of back-siltation appeared at the entrance area and lower reach, which is comparable with the prediction from the model.

With the successful construction of YH101 and increasing of dredging capacity, the Phase III Improvement Project achieved the designed $12.5 \mathrm{~m}$ water depth in the $92.2 \mathrm{~km}$ long, $350-400 \mathrm{~m}$ wide navigation channel, and passed completion acceptance on Mar.14, 2010. After that, the navigation channel came to run on a trial period. To identify the long-term effects of the engineering work YH101 quantitively, it is crucial to collect more field data, such as morphological change, hydrology and sediment data, back-siltation volume and its distribution, for further analyses. So far, the total volume of back-siltation in the $12.5 \mathrm{~m}$ depth navigation channel is still relatively big, further studies are necessary to reduce the maintenance volume.

\section{REFERENCES}

Fan Q.J., 2008. Report: Causes of Back-siltaton of North Passage and analysis on engineering effect of the prososed engineering measure, Yangtze Estuary Waterway Administration Bureau, MOT, China.

Qi D.M, 2007. Report: Preliminary study on the causes of heavily back-siltation of the navigation channel in the North Passage, Shanghai Estuarine and Coastal Scientific Research Center. 
Zhu J.F, 2008. Report: Field Survey and Analyzation on the Effect of Dredging Operation Technologyin the Phase III of Yangtze Estuary Deepwater Channel Regulation Works, Yangtze Estuary Waterway Administration Bureau, MOT, China 